\title{
Erratum to: Volume 68, Earth, Planets and Space
}

Earth, Planets and Space*

\section{Erratum to: Earth, Planets and Space (2016)}

Due to an error in the processing of the below referenced articles of the journal Earth, Planets and Space, articles Chang et al. (2016), Chen et al. (2016), Hong et al. (2016), Isse et al. (2016), Matsuyama and Iwamori (2016), Nishizawa et al. (2016), Ohyama et al. (2016), Sakai et al. (2016) and Zhang et al. (2016) were published with the incorrect journal name in the header of the PDF. The journal was referenced as "Earth Planet Sp", but it should have been referenced as "Earth, Planets and Space".

Each article has since been updated with the correct journal name.

The publisher takes full responsibility for this error and sincerely apologises for the inconvenience caused.

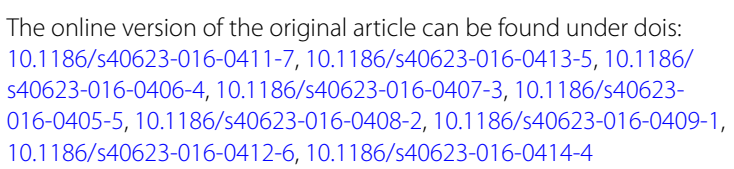

Received: 9 June 2016 Accepted: 9 June 2016

Published online: 18 July 2016

\section{References}

Chang W, Chen K, Tsai Y (2016) An updated and refined catalog of earthquakes in Taiwan (1900-2014) with homogenized Mw magnitudes. Earth Planets Space 68:45. doi:10.1186/s40623-016-0414-4

Chen CH, Saito A, Lin CH, Yamamoto M, Suzuki S, Seemala GK (2016) Medium-scale traveling ionospheric disturbances by three-dimensional ionospheric GPS tomography. Earth Planets Space 68:32. doi:10.1186/ s40623-016-0412-6

Hong J, Romaine S, The MiXO team (2016) Miniature lightweight X-ray optics (MiXO) for surface elemental composition mapping of asteroids and comets. Earth Planets Space 68:35. doi:10.1186/s40623-016-0409-1
Isse T, Sugioka H, Ito A, Shiobara H, Reymond D, Suetsugu D (2016) Upper mantle structure beneath the Society hotspot and surrounding region using broadband data from ocean floor and islands. Earth Planets Space 68:33. doi:10.1186/s40623-016-0408-2

Matsuyama T, Iwamori H (2016) Analysis of plate spin motion and its implications for strength of plate boundary. Earth Planets Space 68:36. doi:10.1186/s40623-016-0405-5

Nishizawa A, Kaneda K, Oikawa M (2016) Crust and uppermost mantle structure of the Kyushu-Palau Ridge, remnant arc on the Philippine Sea plate. Earth Planets Space 68:30. doi:10.1186/s40623-016-0407-3

Ohyama H, Nagahama T, Mizuno A, Nakane H, Ogawa H (2016) Observations of stratospheric and mesospheric $\mathrm{O}_{3}$ with a millimeter-wave radiometer at Rikubetsu, Japan. Earth Planets Space 68:34. doi:10.1186/ s40623-016-0406-4

Sakai H, Fujii R, Sugimoto M, Setoguchi R, Paudel MR (2016) Two times lowering of lake water at around 48 and 38 ka, caused by possible earthquakes, recorded in the Paleo-Kathmandu lake, central Nepal Himalaya. Earth Planets Space 68:31. doi:10.1186/s40623-016-0413-5

Zhang S, Zhao L, Li X, Cheng B (2016) A sequential and partial ambiguity resolution strategy for improving the initialization performance of mediumbaseline relative positioning. Earth Planets Space 68:29. doi:10.1186/ s40623-016-0411-7

*Correspondence: editorial@earth-planets-space.com

BioMed Central, Floor 6, 236 Gray's Inn Road, London WC1X 8HB, UK 